\title{
Derician Trialism: The Concept of Human Composition into the Mind, Submind and Body Substances/Components
}

\author{
Kong Derick Njikeh \\ Faculty of Medicine and Biomedical Sciences, University of Yaounde I, Yaounde, Cameroon \\ Email address: \\ kongderick@yahoo.com \\ To cite this article: \\ Kong Derick Njikeh. Derician Trialism: The Concept of Human Composition into the Mind, Submind and Body Substances/Components. \\ International Journal of Philosophy. Vol. 7, No. 1, 2019, pp. 17-19. doi: 10.11648/j.ijp.20190701.12
}

Received: December 20, 2018; Accepted: January 15, 2019; Published: January 28, 2019

\begin{abstract}
Trialism is a term that is been used in Christian Theology, which is the doctrine that human is made up of three components which are; the Spirit, the Soul and the Body, giving rise to what is known as Christain Trialism. The term trialism was introduced in philosophy by John Cottingham as an alternative interpretation of the Cartesian Dualism (Mind-Body dualism) of Rene Descarte, by adding a third substance called Sensation in what he termed as Cartesian Trialism (MindSensation-Body trialism). Going in line with the trialism nature of human by Cottingham, I think that the third substance Sensation is limited in explaining the processes between the Mind and the Body. So, I think that the substance Sensation should be replaced with the substance which I call "Submind" which is involved with the processes of memories, sensations, emotions and reflexes, which lead to what I term "Derician Trialism" (Mind-Submind-Body trialism). I believe that the mind is involved with high level consciousness, the Submind is involved with low level consciousness and the body has no consciousness.
\end{abstract}

Keywords: Derician Trialism, Christian Trialism, Cartesian Trialism, Cartesian Dualism, Mind, Submind, Body, Consciousness

\section{Introduction}

In Christian theology, trialism is the doctrine that human is made up of three components which are the Spirit, the Soul and the Body [1]. Trialism was introduced in philosophy by John Cottingham as an alternative interpretation of the Cartesian dualism (mind-body dualism) of Rene Descartes, which states that human is made up of two substances; the Mind and Body which are distinct and separable with the Mind being a non-physical substance which holds consciousness [2]. In Cartesian Trialism by Cottingham, he kept the two substances in cartesian dualism and introduce a third substance or attribute called Sensation which belongs to the union of the Mind and Body.

Going in line with the three attribute (Mind, Sensation, Body) nature of human by Cottingham, I think that the third substance (Sensation), is limited in explaining the processes that takes place between the Mind and the Body. This is because Sensation is based mostly in the perception of the senses and doesn't take into consideration the sub-thinking processes involving memories, emotions and reflexes. I think that the substance "Sensation", in Cartesian trialism should be replaced with the term "Submind" in what I called "Derician Trialism" which involves; the Mind, Submind and Body. This Submind is equivalent to the soul component in Christian trialism and the subconscious state in neuroscience.

\section{The Mind Substance/Component}

The Mind was defined by Decartes as a non-physical substance which is involved with the attribute of thought. He identified the mind with consciousness and said that it can exist outside the body [3]. This is compatible with the Spirit component in Christian theology which is said to be nonphysical, existing in the invisible world in communication with the creator, through which everything arises and the main determinant of bodily actions [4]. This aspects of the Mind goes in line with the thoughts of idealism which states that the mental processes (the Mind/Consciousness) are the origin of physical/material processes (bodily actions) and also with the thoughts of Anaxagoras (480BC) that all things were created by the Mind and held that the Mind held the 
cosmos together and gave human beings a connection to the cosmos or a pathway way to the divine [5].

The Mind is also involved with imagination which is the process of higher thinking giving rise to "high level consciousness". This process of imagination is the attribute which makes the Mind to be attributed only to human. Concerning the aspect of neuroscience, the Mind is comparable to the conscious state of being which neuroscientists are struggling to define in terms of physical processes. But I think that this can't be defined because it's more plausible that mental processes are the origin of physical processes and not physical processes being the origin of mental processes.

The Mind is there for the substance or component involve with the attribute of higher thinking (imagination) which gives rise to "high level consciousness". This is equivalent to Access consciousness (A-consciousness) proposed by Ned Block, higher-order consciousness proposed by Gerald Edelman and a combination of self-consciousness and cosmic consciousness proposed by Richard Bucke [6-8]. This attribute makes the Mind to be attributed to humans only and not other animals.

\section{The Submind Substance/Component}

I think that the Submind is the intermediary substance which units the Mind and the Body and has both nonphysical and physical properties. I believe that it is involve with the process of lower thinking including memories, sensations, emotions and reflexes which gives rise to "low level consciousness", defining the non-physical aspect of the Submind. It is also involve with the process of neuronal activities giving rise to impulses which defines the physical aspect of the Submind. Cottingham proposed Sensation as a third attribute/substance in Cartesian trialism but I think that Sensation alone is limited because it doesn't include memories, emotions and reflexes. So, I think it should be replaced with the attribute/substance which I called "Submind" which involves the processes of sensations, memories, emotions and reflexes.

The Submind should be considered as the second attribute/substance in trialism with the Mind and Body being the first and third substances respectively, giving rise to what I term "Derician Trialism". This Submind is compatible with the notion of the soul component in Christian trialism which is considered as a link between the Spirit and the Body, the essence of life and separable from the body during death. Considering the aspect of neuroscience, the Submind is compatible to the Subconscious state of being which deals with the aspects of memories, sensations, emotions and reflexes. I think that the Submind rather than the Mind, is involves with the phenomenon of functionalism in which mental processes are reduced to neuronal activities, which I think just defines the physical aspect of the Submind.

Taking into consideration the different fields of thought (Philosophers, Theologians and Neuroscientists), I can summarize that the Submind is the "body" of the Mind and the "mind" of the Body. This means that, the Mind and the Submind can act separately from the Body as it happens in some aspects of dreams and the period after death (a Ghost). Also, the Submind and Body can act separately from the Mind as it happens during the processes of reflexes, memories, sensations and emotions.

The Submind is therefore the substance involve with the processes of lower thinking including memories, sensations, emotions and reflexes which gives rise to "low level consciousness". This consciousness is equivalent to phenomenal consciousness (P-consciousness) proposed by Ned Block, primary consciousness proposed by Gerald Edelman and simple consciousness proposed by Richard Bucke [6-8]. Taking into consideration all this explanations about the Submind, it is therefore a substance which exists in humans and other animals. This also goes in line with the "Cambridge Declaration on Consciousness" signed by eminent neuroscientist which states that animals also have consciousness [9].

I believe that the consciousness of the Submind is transmitted as encoded information in brain waves which are electromagnetic waves that can explain the process of telepathy [10]. The consciousness of the Submind is what can be attributed also to "Artificial Intelligence" and "Philosophical Zoombies".

\section{The Body Substance/Component}

The Body is the third substance in the trialism nature of human. It is defined as the physical or material substance which exists in the visible world and it is involved with the actions carried out by human which marks the existence of living. The body doesn't think which makes it to be nonconscious in which I attributed the term "unconscious component" [4]. The Body is considered as same substance in philosophy, theology and neuroscience. But there are some idealist philosophers who believe that the materials substances in the universe including the human Body, doesn't exist for it is an illusion [5]. But I think that physical substances do exist and there is the non-physical and physical universe which acts together as a single entity with two components, giving rise to the "dualistic nature of the universe" [4]. The Body is therefore a substance which doesn't have consciousness and it is found in both human and other animals.

\section{Interaction Between the Substances/Components in Trialism}

The three components of human interact in a definite pattern for human existence in this physical world. The Mind interacts with the Submind and the Submind interacts with the Body. I believe that there is no direct interaction of the Mind with the Body. The Mind can acts separately from the Submind and Body in the invisible world such as in the case of some dreams in which human have no memory of. I 
believe that the Submind cannot act separately on its own. Either it is together with the Mind in which it acts as the "body" of the Mind such as in the case of memorable dreams and the period after Body death when the Mind and Submind separate from the Body to form what I consider as a "Ghost". Or it is together with the Body in which it acts as the "mind" of the Body such as in the case of memories, sensations, emotions and reflexes. The Body cannot exist separately in this physical world because it is non-conscious and will always need the Submind for it to carry out its actions of living.

I believe that there are three stages of existence of human in the universe which are; the physical stage in which the Body is the main actor, the intermediary stage in which the Submind (Soul) is the main actor while the Body exist no more and the non-physical stage in which the Mind (Spirit) is the last actor while the Submind exist no more. It should be noted that the combination of the Mind, Submind and body gives a Human, the combination of the Mind and Submind while the Body exist no more gives a Ghost and the Spirit is left alone while the Submind exist no more.

\section{Conclusion}

In the "Derician Trialism" which comprises of the Mind, Submind and Body, the Mind is the first component which is involve with imagination giving rise to "high level consciousness", the Submind is the second component which is involve with memories, sensations, emotions and reflexes giving rise to "low level consciousness" and the Body is the third component which has no consciousness and is involve with performing actions which marks the state of living. These components interact in a linear pattern and the three components are found in human meanwhile just two components (Submind and Body) are found in other animals.

\section{References}

[1] Trialism, Wikipedia, the free encyclopedia.

[2] Cottingham J. (1985) Cartesian Trialism. Mind, 94, 218-230.

[3] Robinson, Howard, (2003) Dualism. The Stanford Encyclopedia of Philosophy.

[4] Njikeh K. D. (2018) Human Existence and the Universe. Books, Kindle Direct Publishing. ISBN 9781719935432.

[5] Idealism, Wikipedia, the free encyclopedia.

[6] N. Block, O. Flanagan, G. Guzeldere. (1998) The Nature of Consciousness: Philosophical Debates. MIT Press. pp. 375415. ISBN 978-0-262-52210-6.

[7] Gerald M. Edelman, Giulio Tononi (2000). A Universe of Consciousness: How Matter Becomes Imagination. Basic Books. ISBN 0-465-01376-7.

[8] Richard M. Bucke (1905). Cosmic Consciousness: A Study in the Evolution of the Human Mind. Innes \& Sons. pp. 1-2.

[9] (PDF) Cambridge Declaration on Consciousness (2012).

[10] Njikeh, K. D. (2014) Electromagnetic Wave and Gaseous Communication between Individuals. Neuroscience \& Medicine, 5, 20-22. http://dx.doi.org/10.4236/nm.2014.51004. 